\title{
Internacionalização e pós-graduação: a política de editais da Capes (2005-2018)
}

\author{
Internationalization and postgraduate studies: \\ Capes public notice policy (2005-2018)
}

\author{
Alda Castro Araújo ${ }^{1}$ \\ Larissa Fernandes ${ }^{2}$
}

Resumo: Este artigo analisa a política de internacionalização da pós-graduação no Brasil induzida pela Capes por meio de Editais no período de 2005 a 2018. Tem como pressuposto que esses editais são articulados com as diretrizes do Ministério de Ciência, Tecnologia e Inovação e com os Planos Nacionais de PósGraduação (2005/2010 e 2011/2020). Para a consecução do estudo, foram realizadas análises documentais e elaboradas séries estatísticas de dados disponibilizados em sítios da Capes. Conclui-se que a internacionalização da pós-graduação é compreendida como estratégia para o desenvolvimento do país, e que os editais estimulam a concorrência institucional e de pesquisadores em claro alinhamento aos objetivos da globalização mercantil.

Palavras-chave: Ciência e Tecnologia. Inovação. Internacionalização. Pós-graduação. 
Abstract: The article analyze the internationalization policy of postgraduate studies in Brazil, induce by Capes through Public Notices from 2005 to 2018. It assumes that these notices are articulated with the guidelines of the Ministry of Science Technology and Innovation and with the Plans National Graduate Programs (2005/2010 and 2011/2020). For the study, statistical and documentary analysis were performed with data provided in Capes sites. It concluded that the internationalization of postgraduate studies is understood as a strategy for the development of the country, and that the calls for big encourage institucional competition and research in clear alignment with objectives of market globalization.

Keywords: Science \& Technology. Innovation. Internationalization. Postgraduate studies.

${ }^{1}$ Universidade Federal do Rio Grande do Norte | Programa de Pós-Graduação em Educação | Natal| RN | Brasil. Contato: aldacastro01 @ hotmail.com. ORCID: https://orcid.org/0000-0001-6740-6257

${ }^{2}$ Universidade Federal do Rio Grande do Norte | Programa de Pós-Graduação em Educação | Natal| RN | Brasil. Contato: larissamfernandes@ hotmail.com. ORCID: https://orcid.org/0000-0001-9434-2236

- Recebido em: 1 de fevereiro de 2021

- Aprovado em: 3 de maio de 2021

DOI: http://dx.doi.org/10.1590/S1414-40772021000200013

Este é um artigo publicado em acesso aberto sob uma licença Creative Commons https://creativecommons.org/licenses/by-nc/4.0/ 


\section{Introdução}

A internacionalização da educação superior não é uma novidade, mas na atualidade ganha uma nova dinâmica, marcada pelo rápido avanço da ciência e das tecnologias da comunicação e da informação, o que implica novas demandas para a pós-graduação, considerada o lócus da produção do conhecimento e da pesquisa. Com a globalização, especialmente após 1970, o conhecimento adquiriu maior centralidade, com o intuito de se adequar à nova configuração mundial. Nesse contexto, passou-se a exigir uma busca cada vez maior pela educação em seus vários níveis, uma maior capacidade instalada de pesquisa e uma formação de recursos humanos mais bem qualificada e desenvolvida internacionalmente. Nesse contexto, a internacionalização da educação superior foi considerada uma ferramenta capaz de promover o desenvolvimento científico, tecnológico e econômico dos Estados-nacionais.

Este artigo objetiva analisar a política de internacionalização da pós-graduação no Brasil induzida pela Capes por meio de Editais no período de 2005 a 2018. Para a consecução desse objetivo, discute-se, inicialmente, as demandas do contexto globalizado e sua influência para o campo educacional, com destaque para os processos de internacionalização da pós-graduação. No segundo momento, analisa-se os instrumentos de planejamento nacionais como as diretrizes do Ministério da Ciência e Tecnologia (MCT) e os Planos Nacionais de Pós-graduação dos períodos de 2005-2010 e de 2011-2020, com foco nas orientações para a internacionalização da educação. O terceiro momento avalia a política de internacionalização implementada pela Coordenação de Aperfeiçoamento de Pessoal de Nível Superior (Capes), tendo como referência os Editais do período 2005 a 2018.

\section{Internacionalização da pós-graduação: as demandas do contexto globalizado}

A internacionalização é um processo que vem se configurando em todos os campos da sociedade e está associada à intensificação do processo de globalização e ao desenvolvimento das novas Tecnologias da Informação e Comunicação (TIC). Cox (2005) aponta vários fatores que tornam a internacionalização da educação superior uma necessidade, entre eles o fato de que ela representa um mecanismo de resposta aos desafios da globalização. Para essa autora, "a interdependência das economias e sociedades de hoje afeta profundamente a educação superior, e essa por sua vez, molda a globalização - por meio de ensino, pesquisa e outros serviços" (COX, 2005, p. xi).

As definições de internacionalização acompanham a configuração dos contextos socioeconômicos, que são modificados historicamente. De acordo com Knight (2005, p. 14), a internacionalização da educação superior pode ser definida, no estágio atual do capitalismo, 
como o processo de integrar uma dimensão internacional ou intercultural, com as funções de ensino, investigação e serviço da instituição. Portanto, trata-se de uma definição que abrange tanto suas potencialidades no campo da cooperação acadêmica como de mercantilização dos serviços de educação superior.

Vista nessa perspectiva, a internacionalização da educação superior é colocada em uma condição complexa. Ela possui a dupla função de estabelecer vínculos de cooperação para o desenvolvimento de uma ciência de base e desinteressada e de realizar o próprio projeto de mercadorização da educação superior e seus produtos em um contexto global, para atender às demandas de uma base produtiva.

A internacionalização da educação superior é uma das estratégias utilizadas pelos países para reagirem aos desafios impostos pela globalização da economia e do conhecimento, por meio de várias iniciativas, entre elas, os intercâmbios acadêmicos, a circulação de Programas, a abertura de campi e a instalação de instituições fora do país de origem (KNIGHT, 2002). Nesse sentido, Knight (2005, p. 1, tradução nossa) explicita que

\begin{abstract}
o mundo do ensino superior e o mundo em que o ensino superior desempenha um papel significativo estão mudando, por muitas razões. Os principais fatores incluem o desenvolvimento de serviços avançados de comunicação e tecnologia, maior mobilidade internacional do trabalho, maior ênfase na economia de mercado e liberalização do comércio, foco na sociedade do conhecimento, maior investimento privado e menor apoio público à educação e a crescente importância da vida inteira aprendendo.
\end{abstract}

A autora considera que, diante de fatores contextuais especificados, a internacionalização da educação superior é capaz de se reconfigurar internamente, bem como reconfigurar muito de seu contexto exógeno, ou seja, a própria organização das sociedades por ela afetada (KNIGHT, 2005). Nesse cenário, a pós-graduação, por relacionar-se intimamente com a formação docente para a educação superior, com produção de novos conhecimentos por meio da pesquisa e da formação da mão de obra altamente qualificada, passou a ser prioridade no processo de inter-relacionamento internacional, no qual o maior objetivo é o aumento da competitividade econômica, além da própria geração de um verdadeiro mercado global de serviços na educação de nível superior. De acordo com Castro (2010, p. 6), esse processo gera

[...] um consenso emergente de que no âmbito da economia globalizada a produção de uma força de trabalho, educada segundo padrões internacionais, é mais importante que nunca, e deve passar a fazer parte da infraestrutura proporcionada pelo Estado, tornando-se, assim, necessária para aumentar a vantagem competitiva das nações. 
Segundo a autora, o processo de globalização e, consequentemente, o processo de internacionalização da educação superior têm como um de seus principais objetivos a padronização de um modo de conceber conhecimento e práticas a partir de um modelo considerado mais adequado à sociedade vigente. Na visão de Siufi (2009), essa padronização acarreta um processo de exclusão daqueles com menores possibilidades de competitividade, pois está pautada, sobretudo, na eficácia individual e na competência do mercado nacional para competir no mercado global. A corrida pelo protagonismo competitivo em escala global, por sua vez, aprofunda as atitudes individualistas e faz perder o foco de solidariedade, a partir do qual os Estados e suas instituições poderiam mutuamente se ajudar para resolver seus problemas comuns.

Nesse contexto, os objetivos da internacionalização, com ênfase na integração econômica, conforme orientação de organismos internacionais que a colocam como "transnacionalização", têm fortalecido uma concepção de educação mercantil. Desenvolve-se, segundo Chaves (2010), uma ampla possibilidade de mobilizar divisas entre os países, por meio da financeirização da educação superior no mercado de ações provenientes da valorização desse setor, formando grandes oligopólios no âmbito do setor privado.

Para os Estados economicamente desenvolvidos, as atividades de intercâmbio significam, sobretudo, ganho econômico com taxas, inscrições e gastos gerais de estudantes, com dinheiro proveniente de bolsas de estudos concedidas por seus países de origem ou mesmo com dinheiro privado das famílias; promoção cultural de seu país, tanto em relação aos costumes quanto à língua; mão de obra qualificada, mesmo que por pouco tempo, quase sem custo para o Estado; controle imigratório; captação de cérebros, quando é possibilitado o retorno do estudante, já como profissional, ao país que realizou intercâmbio; fortalecimento da pesquisa e da produção do conhecimento em virtude do domínio de patentes (LIMA; MARANHÃO, 2009). Todas essas atividades têm sido associadas às áreas estratégicas do conhecimento, geralmente relacionadas ao que se exige de mais urgente no setor produtivo, e têm sido fomentadas por organismos internacionais.

Evidencia-se o caráter contraditório posto na internacionalização da educação superior, advindo do fato de ela estar diretamente associada ao atual estágio de desenvolvimento das relações sociais e econômicas do processo de globalização, fazendo com que o ideal de cooperação solidária seja frequentemente posto em dúvida, pois os interesses institucionais e econômicos têm se sobressaído devido à busca de possibilidade de competitividade entre indivíduos, grupos, instituições e Estados. Esclarecendo esse posicionamento, Siufi (2009, p. 125, tradução nossa) faz a seguinte colocação: 
O que descrevemos sobre a cooperação, entendida como uma integração fraterna entre países e entre instituições universitárias, discorda da definição de globalização, como fenômeno que se estende à custa da diversidade e autonomia dos estados nacionais, das identidades culturais e, sobretudo, das necessidades humanas, com efeitos econômicos, sociais, geográficos e políticos; que inegavelmente afetam a educação.

Fazer com que haja cooperação em um contexto em que os objetivos estão mais relacionados à padronização, à competitividade, à individualidade e ao crescimento econômico é uma tarefa naturalmente contraditória. Trata-se de dois processos que a autora considera incompatíveis no sistema capitalista: a cooperação internacional universitária, pelos caminhos da solidariedade mútua, e o processo de globalização, entendendo que este último torna inviável o primeiro por sua própria natureza polarizadora, intensificadora das desigualdades em vários âmbitos da sociedade. Sendo a internacionalização, portanto, parte e resultado desse processo, tende a possuir as mesmas características de sua base constitutiva.

A internacionalização apresenta potencial de desenvolvimento inegavelmente positivos, como a integração que permite o fortalecimento dos sistemas de educação superior, principalmente no que concerne à pesquisa e pós-graduação, desde que tratada como instrumento de produção do conhecimento em uma situação de construção conjunta em busca de resolução de problemas de todos os partícipes desse processo. Todavia, na atualidade tem sido usada mais para proporcionar o fomento de um verdadeiro comércio de conhecimento, intensificando a dualidade existente entre os países que sempre estiveram à frente da produção do conhecimento e aqueles que vivem na periferia do processo produtivo.

\section{A internacionalização da pós-graduação e sua articulação com a política de CT\&I}

A internacionalização da educação superior é historicamente utilizada como estratégia de socialização do saber por ela produzido, especialmente quando se refere ao pilar da pesquisa como produtora do novo conhecimento. De acordo com Morosini (2006, p. 108), "por sua natureza de produtora de conhecimento, a universidade sempre teve como norma a internacionalização da função pesquisa, apoiada na autonomia do pesquisador", diferentemente com o que ocorre com a função do ensino em seu nível de graduação, que, ao considerar o caso brasileiro, é fortemente controlado pelo Estado.

Portanto, a internacionalização nesse nível de educação acontecia, conforme Morosini (2006), por ações individuais dos próprios pesquisadores, porém, com o processo de estreitamento das relações propiciado pela globalização do capital, o Estado brasileiro passou a sistematizar políticas públicas de desenvolvimento de uma internacionalização da pós- 
graduação por meio de fomento institucional acadêmico para viabilizar o processo. Para Morosini e Nascimento (2017), a internacionalização da educação superior, de modo geral, “[...] vem se constituindo em um dos principais motes da universidade na contemporaneidade. Via de regra, ela está relacionada à qualidade, à excelência, à inovação, ao conhecimento e a outros diferentes temas $[\ldots] "$.

O processo de internacionalização da pós-graduação é impulsionado, no Brasil, com a criação da Capes em 1951, e com a aprovação do Parecer n. 977 de dezembro de 1965. A institucionalização da Capes significou maior desenvolvimento de pesquisas voltadas para a formação de recursos humanos, que tinham como objetivo a modernização do país. No entanto, enquanto uma diretriz a ser seguida, somente aparece no Plano Nacional de Pós-graduação 2005-2010, sob a perspectiva, da solidariedade. Segundo a instituição,

\footnotetext{
deve-se estimular a cooperação internacional por intermédio das universidades, de tal forma que o intercâmbio entre alunos e professores seja institucionalizado, permitindo a apresentação de projetos de capacitação de recursos junto às agências de fomento internacionais (BRASIL, 2004b, p. 61-62).
}

A Capes (BRASIL, 2004b) afirma a necessidade de estimular uma internacionalização nos moldes da cooperação internacional. Destaca também a importância da institucionalização desse processo, haja vista que ele representa, para o Sistema Nacional de Pós-graduação, maior visibilidade internacional e a possibilidade de competir mundialmente por um maior espaço de influência nos rankings internacionais. Adotando o modelo gerencial da administração pública, a Capes responsabiliza os programas de pós-graduação pela iniciativa, via projetos e concorrência de editais, em buscar os recursos financeiros necessários às suas ações de internacionalização, junto às agências de fomento, o que os coloca naturalmente em uma situação de competitividade interna na corrida por uma maior inserção internacional de seu corpo discente e docente, bem como de suas pesquisas. Os documentos de planejamento que orientaram as diretrizes da Pós-graduação, trouxeram um forte incentivo das agências de fomento à pesquisa nacional para proporcionar o intercâmbio acadêmico-estudantil, com financiamento nacional e/ou internacional.

A partir da década de 2000, pode-se evidenciar a existência de uma ação articulada entre os Planos Nacionais de Pós-graduação (2005-2010 e 2011-2020) e as diretrizes do atual Ministério da Ciência e Tecnologia (MCT), contidas em seus documentos de planejamento como: Livro Verde: sociedade da informação no Brasil (2000); Livro Branco: Ciência, Tecnologia e Inovação (BRASIL, 2002); e Livro Azul: $4^{a}$ Conferência Nacional de Ciência, Tecnologia e Inovação para o desenvolvimento sustentável (BRASIL, 2010a), as diretrizes 
desses livros tinham como finalidade estimular um maior desenvolvimento da pesquisa nacional. Os marcos legais que possibilitaram a prática dessa política estão contidos na promulgação de leis como: Lei $n^{\circ}$. 10.973, que dispõe sobre incentivos à inovação e à pesquisa científica e tecnológica no ambiente produtivo e dá outras providências (BRASIL, 2004a); a Lei $n^{\circ}$. 11.196-Lei do Bem- (BRASIL, 2005), que concede incentivos fiscais às empresas que investem em pesquisa e desenvolvimento de inovação tecnológica; e, em 2016, a Lei nº 13.243 que, dispõe sobre estímulos ao desenvolvimento científico, à pesquisa, à capacitação científica e tecnológica e à inovação e altera a Lei n. 10.973, de 2 de dezembro de 2004.

Há, portanto, expressivo esforço por parte do Estado brasileiro em incentivar o desenvolvimento da pesquisa nacional. Entretanto, esse esforço está associado fortemente ao segmento privado, às bases de produção capitalista e a áreas específicas, conferindo um caráter mais utilitário à pós-graduação. Dessa forma, o Estado brasileiro tem posicionado a pósgraduação nacional de maneira cada vez mais submissa aos interesses mercantis, o que justifica sua necessidade de articulá-la a setores e agências mais próximos ao próprio mercado.

No que diz respeito às diretrizes do MCT, em seu primeiro documento, o Livro Verde (2001), é possível evidenciar no excerto abaixo o lugar da pesquisa no desenvolvimento nacional,

\footnotetext{
o alto investimento na pesquisa, o crescimento do número de professores, engenheiros, técnicos, cientistas e pesquisadores, inclusive com a incorporação de cientistas estrangeiros, a organização de grandes programas científicos e tecnológicos mobilizadores, a existência de numerosas e importantes empresas de base tecnológica são aspectos que refletem a busca seletiva dessas sociedades por liderança no progresso do conhecimento (BRASIL, 2001, p. 48).
}

Logo, pode-se perceber que, embora o referido documento ao mesmo tempo que ressalta a importância da pesquisa, dos pesquisadores e da inserção de cientistas estrangeiros no desenvolvimento de conhecimento de ponta, dissemina também uma visão mercantilista da pesquisa, pois a coloca no campo de áreas relacionadas à produção de mercadorias e serviços capazes de promover a inovação, elencando a categoria de profissionais nomeadamente do campo das engenharias e da participação de empresas de base tecnológica. Põe, desse modo, as Ciências Sociais como coadjuvantes, importantes apenas para o estabelecimento de relações entre Ciência e Tecnologia (C\&T), ou seja, para o trabalho de conformação da sociedade a esse modelo.

O segundo, o Livro Branco (BRASIL, 2002) é uma consolidação das diretrizes do Livro Verde, nele é notório que o relacionamento entre universidades e empresas deve ser perseguido como forma de melhorar o desempenho da pesquisa aplicada. Há, portanto, uma forte ligação 
entre as orientações desses documentos e os marcos legais da Ciência e Tecnologia, entre elas podemos destacar a Lei n. 10.973, de 2004, e a Lei n. 11.196, de 2005, nas quais se verifica um incentivo ao desenvolvimento da pesquisa em áreas prioritariamente relacionadas à inovação e à tecnologia em ambientes produtivos, bem como a concessão de incentivos fiscais para que as empresas engajem nesse processo junto às instituições de pesquisa desse país.

As normativas e diretrizes do Ministério da Ciência, Tecnologia e Inovação repercutiram nos PNGs da época. O PNPG (2005-2010), elaborado ainda no contexto das diretrizes dos Livros Verde e Branco, afirma que "cabe à pós-graduação a tarefa de produzir os profissionais aptos a atuar nos diferentes setores da sociedade e capazes de contribuir, a partir da formação recebida, para o processo de modernização do país” (BRASIL, 2004b, p. 8). Enfatiza, dessa forma, a urgência de se estabelecer uma relação mais dinâmica e comprometida, entre a área acadêmica e o setor produtivo, com a finalidade de " [...] formar profissionais para serem absorvidos pela indústria e criar condições para o surgimento de novas empresas brasileiras a partir do conhecimento gerado na pós-graduação” (MANCEBO, 2008, p. 180).

O Livro Azul, de 2010, é um documento que, para Kato (2013, p. 98),

[...] traz à tona novos arranjos institucionais para implementação das recomendações do Plano de Ação da Ciência, Tecnologia e Inovação, entre eles: a inovação [...] a ampliação dos investimentos públicos e dos investimentos privados em P\&D; o preparo de empresas e do país para um ambiente de competição global, visando ao estímulo à internacionalização.

Nessa análise é possível perceber que baseado nessa diretriz, o próprio Estado brasileiro incorporou no ano de 2006 o termo "inovação" ao MCT, que passou a se chamar Ministério da Ciência, Tecnologia e Inovação (MCTI). O conceito de inovação já vinha sendo discutido pelo Banco Mundial desde 2008, na ocasião apresentava algumas características para o entendimento do conceito de inovação como: 1) a criação e a comercialização de novos conhecimentos e tecnologia; 2) a aquisição e a adaptação da tecnologia estrangeira para usos locais; e 3) a disseminação e a aplicação eficaz do conhecimento e da tecnologia, seja ela de criação endógena, seja exógena (BANCO MUNDIAL, 2008). Portanto, a inovação pode ser entendida como a capacidade de criar ou produzir tecnologia que fará com que o Estado possa se inserir nesse contexto global.

O PNPG (2011-2020) incorpora a discussão de "inovação" como um novo padrão a ser priorizado o que ressalta a importância de uma articulação mais estreita entre a universidade e a empresa. No entanto, também se verifica nas suas diretrizes, o incentivo a uma internacionalização pela via da cooperação, deixando claro que há uma contradição pois ao 
mesmo tempo que alimenta a participação de empresas privadas e estatais no desenvolvimento das pesquisas, também estimula a internacionalização solidária. No PNPG (2011-2020) é possível destacar a internacionalização pela via da cooperação internacional, sob o discurso de que "essa interação, além de promover o crescimento da ciência, aumentará o protagonismo do país no cenário internacional” (BRASIL, 2010b, p. 303). Nesse sentido, aponta três caminhos que devem ser estimulados nesse processo no período de vigência do Plano:

O envio de mais estudantes ao exterior para fazerem doutorado, em vista da dinamização do sistema e da captação do conhecimento novo; o estímulo à atração de mais alunos e pesquisadores visitantes estrangeiros; o aumento do número de publicações com instituições estrangeiras (BRASIL, 2010b, p. 303).

Compreende-se que o processo de internacionalização da pós-graduação brasileira ocorre em um contexto mais amplo de valorização da ciência, por isso, é importante realçar que ciência está sendo fomentada pela Capes, pois é para ela que a agência irá concentrar os esforços e os fomentos. Ainda no último PNPG, é possível verificar (item 13.2.3) que faz parte da política de indução da Capes a criação de Programas em áreas estratégicas, sendo elas: Pró-defesa, Nanobiotecnologia, TV Digital e Pró-Engenharias. Associado a isso, o item 14.10 do texto do PNPG (2011-2020) delimita que o financiamento da Capes deve privilegiar sete ações, dentre as quais cinco estão diretamente relacionadas à promoção da pesquisa em Ciência, Tecnologia \& Inovação (CT\&I).

Associadamente, o Livro Azul atribuiu maior ênfase ao processo de internacionalização, também pela ótica da cooperação, como estratégia para o desenvolvimento científico e tecnológico do país. Nesse sentido, ressalta que é preciso

$$
\begin{aligned}
& \text { promover substancial acréscimo de investimentos em cooperação internacional que } \\
& \text { tenha por objetivo uma produção científica nacional na fronteira do conhecimento e } \\
& \text { uma forte presença da ciência brasileira nas principais instituições e organismos } \\
& \text { internacionais de C\&T de caráter bilateral ou multilateral (BRASIL, 2010b, p. 58). }
\end{aligned}
$$

Registra-se que a política de CT\&I nacional está baseada em um tripé que tem em seus elementos a Ciência, a Tecnologia e a Inovação como elementos-chave para a ampliação das capacidades produtivas do país. O conhecimento, então, é considerado o grande facilitador de um processo cíclico no qual ele por si só não gera riqueza, mas é capaz de contribuir com a produção de produtos e serviços para a comercialização. Assim, a associação academiaempresa é cada vez mais incentivada pelas políticas nacionais.

A internacionalização da pós-graduação, é de fundamental importância para o desenvolvimento endógeno da pesquisa institucionalizada e do setor produtivo. Além disso, é 
relevante como fator de competitividade exógena em um universo que coloca a produção do conhecimento como indispensável para a manutenção do sistema capitalista e, consequentemente, do processo de propagação das desigualdades econômicas e sociais provocadas pela individualização e pela competição entre Estados.

Seguindo as diretrizes dos PNPGs, a Capes tem desenvolvido uma política ideologicamente condizente com as orientações postas pelo atual Ministério da Ciência, Tecnologia, Inovações e Comunicações (MCTIC), que coloca a produção do conhecimento cada vez mais próxima ao que é exigido pelo mercado, em áreas em que este pede maior crescimento. O conhecimento passa a ser produzido muito mais para colocar o Estado em posição de competitividade no mercado externo que para o desenvolvimento sociocultural da nação.

\section{A indução da política de internacionalização da pós-graduação no Brasil em editais da Capes}

$\mathrm{Na}$ atualidade inúmeras agências e instituições de fomento e amparo à pesquisa, atuam no Brasil induzindo políticas que cada vez mais aproximam o conhecimento produzido aos interesses de mercado. No âmbito público, duas agências se destacam a Capes vinculada ao Ministério da Educação, com a atuação muito próxima aos Programas de Pós-graduação e o CNPq vinculado ao Ministério da Ciência e Tecnologia (MCT) e apoiando e fomentando os pesquisadores, a as linhas de pesquisa das instituições. Destaca-se nesse cenário, o papel da Capes, fundada em 1951, por seu caráter organizacional de políticas para a pós-graduação nacional. De acordo com Azevedo, Oliveira e Catani (2016, p. 791), ela é responsável por creditar, credenciar, avaliar, supervisionar, financiar e regular o Sistema Nacional de Pósgraduação brasileiro, bem como incentivar a cooperação internacional e a internacionalização da ciência e da educação superior. De acordo com Kato e Ferreira (2016, p. 683), nos anos 2000, houve

a produção de planos específicos de educação como os Planos Nacionais de Pósgraduação que passam a orientar, juntamente com a Política Industrial Tecnológica e de Comércio Exterior e o PAC da Ciência e tecnologia, a formação e a mobilidade internacional dos estudantes e professores pelo fomento de bolsas de estudos, estágios acadêmicos e participação em eventos internacionais, a criação de novos cursos, a produção do conhecimento, o financiamento das pesquisas e as regras de avaliação. 
É possível constatar, pelos dados publicados pela Capes, que desde o ano de 2004, há uma maior organização da internacionalização por meio de acordos bilaterais e multinacionais, fomentados e regularizados por editais. $\mathrm{O}$ gráfico $\mathrm{n}^{\circ} 01$ permite visualizar o número de Programas de Cooperação estabelecidos pelo Capes entre os anos de 2005 e 2018:

Gráfico 1 - Número de programas de cooperação internacionais de acordo com a modalidade (2005 2018)

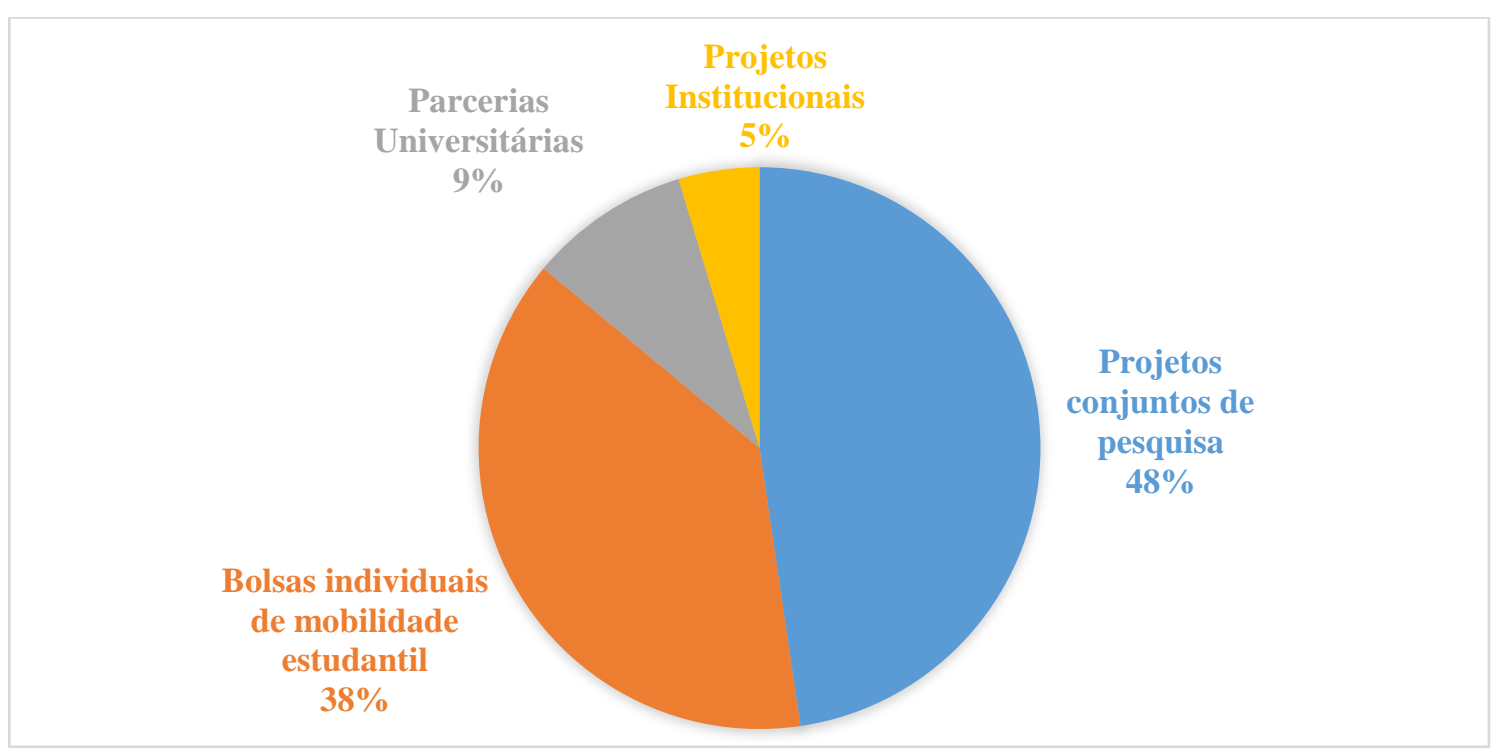

Fonte: Editais da Capes no período de 2005 a 2018 (elaboração dos autores), disponíveis no site oficial da Capes.

A Cooperação Internacional é uma das formas de internacionalização que tem sido priorizada pela Capes O Gráfico 1 mostra o número de Programas de cooperação internacionais de acordo com a seguinte modalidade: projetos conjuntos de pesquisa; bolsas individuais; parcerias universitárias; ou projetos institucionais. Foram firmados pela Capes 86 Programas de cooperação; 41 deles, que correspondem a $48 \%$, visam o estabelecimento de projetos conjuntos de pesquisa; 33 deles, ou seja $38 \%$ dos Programas, estão voltados para a mobilidade estudantil e/ou docente por meio das bolsas individuais; 8 desses programas são do tipo "parceria universitária" correspondendo a 9\%; e 4 deles, "projetos institucionais", em um percentual de 5\% que são voltados para o fortalecimento das instituições universitárias e programas de pós-graduação nacionais em parceria com instituições estrangeiras.

Para Azevedo (2016, p. 78), “o espírito de um acordo internacional entre universidades é o de conferir legalidade e legitimidade à cooperação acadêmica entre atores sociais das Instituições de educação Superior que se propõem a cumprir objetivos postos em comum”. Ou seja, conforme o autor, esses acordos garantem a visibilidade internacional de uma comunidade 
acadêmica e servem também para subsidiar as normatizações dos intercâmbios acadêmico e ir além, legitimando a pesquisa nacional no cenário global.

A Tabela 1, elaborada tomando como referência os dados disponibilizados na plataforma on-line da Capes, permite uma visão geral da configuração do número de editais de internacionalização lançados pela agência no Brasil no período de 2005 a 2018, bem como permite uma visualização dos países que firmaram esses acordos de cooperação.

Tabela 1 - Número de editais de cooperação internacionais por países correlatos (2005-2018)

\begin{tabular}{|c|c|c|c|c|c|}
\hline \multirow[t]{2}{*}{ PAÍSES } & \multicolumn{4}{|c|}{ EDITAIS } & \multirow[t]{2}{*}{$\%$ Total } \\
\hline & $2005-2010$ & 2011-2018 & $\uparrow \%$ & $\begin{array}{l}\text { Total de } \\
\text { Editais }\end{array}$ & \\
\hline Alemanha & 8 & 28 & 250 & 36 & 11,88 \\
\hline Argentina & 8 & 11 & 37,5 & 19 & 6,27 \\
\hline Áustria & 0 & 6 & - & 6 & 1,98 \\
\hline Bélgica & 1 & 2 & 100 & 3 & 0,99 \\
\hline Canadá & 0 & 3 & - & 3 & 0,99 \\
\hline Colômbia & 0 & 1 & - & 1 & 0,33 \\
\hline Espanha & 2 & 4 & 100 & 6 & 1,98 \\
\hline EUA & 16 & 36 & 125 & 52 & 17,16 \\
\hline França & 10 & 25 & 150 & 35 & 11,55 \\
\hline Israel & 0 & 1 & - & 1 & 0,33 \\
\hline Itália & 1 & 1 & 0 & 2 & 0,66 \\
\hline Japão & 1 & 7 & 600 & 8 & 2,64 \\
\hline México & 1 & 0 & - & 1 & 0,33 \\
\hline Noruega & 0 & 3 & - & 3 & 0,99 \\
\hline Países Baixos & 3 & 6 & 100 & 9 & 2,97 \\
\hline Portugal & 5 & 9 & 80 & 14 & 4,62 \\
\hline Reino Unido & 5 & 35 & 600 & 40 & 13,20 \\
\hline Suécia & 0 & 6 & - & 6 & 1,98 \\
\hline Uruguai & 4 & 4 & 0 & 8 & 2,64 \\
\hline Multinacionais & 15 & 35 & 133,33 & 50 & 16,50 \\
\hline TOTAL & 80 & 223 & 178,75 & 303 & - \\
\hline
\end{tabular}

Fonte: Editais da Capes no período de 2005 a 2018 (elaboração dos autores), disponíveis no site oficial da Capes

Os dados demonstram que a Capes, seguindo as orientações de internacionalizar a pósgraduação, priorizou uma política baseada em um planejamento estratégico e sistematizou uma política mais articulada aos documentos elaborados pelo MCT. Portanto, no início do período observado (2005-2010), vigência portanto das diretrizes propostas no Livro Branco (BRASIL, 2002) e no PNPG (2005-2010) a ação da Capes é muito tímida, apesar da necessidade de consolidar a internacionalização como previa os documentos de planejamento nacional. Nesse período foram lançados apenas 80 editais de cooperação, que priorizaram os Estados Unidos com 16 editais e a categoria multinacionais envolvendo diferentes países que chegaram a 15 .

No período de 2010 a 2018, essa política tem uma evolução e o total de editais passou de 80 para 223 , um crescimento de 178 , isto é, $75 \%$ a mais do que no período anterior. Vários 
fatores parecem ter contribuído para esse crescimento, nessa época o país vinha atravessando um período de estabilidade, com crescimento econômico e social que favoreceu a política de expansão da pós-graduação, nesse cenário merece destaque a implementação do Programa Ciência sem Fronteiras, instituído no ano de 2011 pelo Decreto n. 7.642, o qual destinou significativo número de bolsas (25.940) para a mobilidade internacional em nível de pósgraduação (BRASIL, 2011). Também é importante considerar as diretrizes do Livro Azul (BRASIL, 2010a) que previa a necessidade da internaciolização da pós-graduação, com uma clara orientação para as áreas consideradas estratégicas, quais sejam: Agricultura, Bioenergia, Tecnologias de Informação e Comunicação e Pré-Sal.

Pode-se observar ainda na Tabela 1, que considerando os dois períodos analisados, os Estados Unidos aparecem como o país com o qual o Brasil possui maior vínculo internacional, com 52 editais, em segundo lugar encontramos os editais que contemplam vários países, os multinacionais, com 50 editais, seguido do Reino Unido (40), da Alemanha (36) e da França (35). A soberania estadunidense quanto à produção de conhecimento de ponta tem sido historicamente relacionada com o seu papel no comando da divisão internacional do trabalho, sua proeminência como uma potência econômica, militar, científica e tecnológica e com o dinamismo das suas instituições de educação superior. É por esse dinamismo no campo da produção do conhecimento que, de acordo com Lima e Contel (2011), ele se tornou o país com o maior polo de atração de estudantes, pesquisadores e profissionais qualificados. Os Estados Unidos possuem 46 (quarenta e seis) instituições de educação superior entre as 100 (cem) melhores do mundo, segundo o Academic Ranking of World Universities/2018 (ARWU, 2018). A Inglaterra está em segundo lugar, com 8 (oito) instituições, seguida pela Suíça, com 5 (cinco) universidades, pela Alemanha, com 4 (quatro), e pela França, com 3 (três), no ranking, países com os quais o Estado brasileiro mantém o maior número de editais de cooperação internacional.

Ainda de acordo com a Tabela 1, pode-se avaliar que a internacionalização da pósgraduação com os países da América Latina é muito embrionária e reflete a pouca inserção que a região tem no cenário mundial, o que lhe impõe uma posição de dependência em relação a outras economias mundiais, com repercussões na educação superior. Os países com os quais o Brasil estabeleceu editais de cooperação foram: Argentina (19), Colômbia (1), México (1) e Uruguai (8). Pode-se considerar que o baixo número de países com editais em cooperação nesse contexto se refere ao fato de que o Brasil é o país da região que mais se sobressaiu no ranking mundial de melhores universidades do mundo nos últimos anos, o que deixa os países vizinhos em situação de pouca atratividade. Por outro lado, a região não tem uma histórico de grande 
mobilidade e nem um desenvolvimento econômico e tecnológico que seja atrativo para os estudantes. Castro e Cabral Neto (2012) apontam que o processo de mobilidade estudantil para a América Latina, e em especial para o Brasil, ocorre de forma periférica, dificultado pela dependência econômica desses países em relação aos mais desenvolvidos. Poucas são as universidades no continente latino-americano classificadas, em rankings mundiais e quando comparadas com as grandes universidades de regiões desenvolvidas do mundo, essas instituições apresentam um baixo grau de competitividade.

Nesse sentido, é importante destacar que a dinâmica da internacionalização tem sido guiada por rankings internacionais, que "atestam" a qualidade das instituições de educação superior no mundo. Segundo Thiengo (2019), há em curso um processo de constituição de "universidade de classe mundial", orientado por organizações internacionais como o Banco Mundial e a Organização para a Cooperação e Desenvolvimento Econômico, que se utilizam de gráficos, tabelas e resultados de rankings internacionais para fomentar a ideia da criação de centros de excelência e competitividade entre eles.

Os editais multinacionais, que objetivam o inter-relacionamento com vários países simultaneamente, são também expressivos. No entanto, não foi possível contabilizar os países que estão envolvidos, pois, essa informação não está disponibilizada no site. Pode-se inferir que a tendência é a de que, assim como ocorre em outros programas de mobilidade, nos quais a escolha recai sobre países como EUA, Alemanha, Reino Unido e França, esses acordos também privilegiem esses países, na medida em que têm uma forte estrutura de acolhimento para os estudantes, são mais bem situados economicamente e possuem alta capacidade de desenvolvimento científico e tecnológico em instituições, ou seja, constituem-se centros de excelência na área, segundo as avaliações dos rankings mundiais.

Os editais são a operacionalização dos acordos ou convênios, em sua maioria, bilaterais, para a cooperação internacional. Conforme De Wit (2013), por si só, eles não garantem a efetivação da internacionalização da educação superior, uma vez que, mesmo com o acordo estabelecido entre os países ou mesmo entre as instituições, não há garantia que ele se efetive, tendo em vista, que vários fatores devem ser considerados na sua execução, como a infraestrutura, discentes e docentes dispostos a se envolverem em intercâmbio ou em projetos conjuntos de pesquisa. 


\section{Considerações finais}

As políticas educacionais implementadas na década de 1990 foram redimensionadas pelas exigências da globalização e pela adequação ao processo produtivo. Nesse cenário, a internacionalização da educação superior brasileira tem sido considerada instrumento para se garantir o acesso ao conhecimento construído em outras instituições e países que possam contribuir para o desenvolvimento da pesquisa nacional e para a resolução de problemas locais. Essa tem sido uma tendência fortalecida pelas políticas públicas brasileiras para atender às exigências do capital, tendo em vista proporcionar maior interação entre instituições nacionais e internacionais e se fazer competitiva em âmbito global.

Os documentos de planejamento elaborados tanto em nível do MCTI como da MEC entendem que a política de internacionalização da pós-graduação é uma estratégia fundamental para o desenvolvimento nacional e, portanto, as suas diretrizes estão articuladas com as políticas de CT\&I, que têm por base a tríade Ciência, Tecnologia e Inovação como elementos-chave para a ampliação das capacidades produtivas do mercado brasileiro. Nesse sentido, a associação academia-empresa é cada vez mais incentivada pelas políticas nacionais, além de a aquisição de novos conhecimentos em países que estão em estágio mais desenvolvido e possuem tecnologias inovadoras passar a ser uma prioridade.

Dentro de uma ótica gerencial a política de internacionalização da pós-graduação tem sido baseada em editais que incentivam a concorrência de pesquisadores, instituições e áreas do conhecimento para o estabelecimento da cooperação internacional. Essa política tem início no ano de 2005, com o PNPG (2005-2010), e é aperfeiçoada pelo PNPG (2011-2010), que demonstram ter como base teórica uma estreita relação com as diretrizes disseminadas pelo MCT (2001/2010). Dessa forma, dissemina-se uma política de incentivo à pesquisa induzida para fins de desenvolvimento das capacidades produtivas do país, relacionadas a produtos, processos e serviços de cunho mais prático e empresarial.

A internacionalização da pós-graduação é fundamental para o desenvolvimento da pesquisa institucionalizada e do setor produtivo, como também como fator de competitividade exógena. Para a sua operacionalização, a Capes tem lançado mão de editais que estimulam cada vez mais a competição entre os programas de pós-graduação, colocando em vantagem aqueles mais bem qualificados nos sistemas de avaliação, por serem mais bem estruturados e possuírem pesquisadores mais bem articulados no contexto global. Entende-se que a política que tem sido executada pela Capes tendo como objetivo consolidar a internacionalização dos programas de pós-graduação, tem enfatizado a ótica do mercado em detrimento solidariedade entre os 
programas, os editais têm estimulado a concorrência entre instituições e as áreas do conhecimento por uma formação em centros de pesquisa de ponta.

Mesmo reconhecendo as suas limitações, e a sua atuação sendo restrita a um número reduzido de docentes e discentes, é importante registrar o lado positivo da internacionalização, uma vez que permite aos pesquisadores a troca de conhecimento, o estabelecimento de redes de pesquisa ou acordos de cooperação e uma maior visibilidade internacional. Essa estratégia pode contribuir para a melhoria da capacidade produtiva do país, bem como para o processo de formação de pesquisadores de alto nível em todas as áreas.

\section{Referências}

ARWU. ACADEMIC RANKING OF WORLD UNIVERSITIES. 2018. Disponível em: http://www.shanghairanking.com/ARWU2018.html. Acesso em: 10 jun. 2018.

AZEVEDO, Mário_Luiz. A educação superior em tempos de internacionalização: cinco mitos, nove enganos e cinco verdades. In: CUNHA, C.; SOUSA, J. V.; SILVA, M. A. (org.).

Internacionalização da educação: discursos, práticas e reflexos sobre as políticas educativas. Belo Horizonte: Fino Traço, 2016. p. 71-90.

AZEVEDO, Mario Luiz; OLIVEIRA, João Ferreira; CATANI, A. M. O sistema nacional de pós-graduação (SNPG) e o Plano Nacional de Educação (PNE 2014-2024): regulação, avaliação e financiamento. Revista Brasileira de Política e Administração da Educação, Goiânia, v. 32, n. 3, p. 783-804, set./dez. 2016.

BANCO MUNDIAL. Conhecimento e inovação para a competitividade. Tradução da Confederação Nacional da Indústria. Brasília: CNI, 2008.

BRASIL. Casa Civil. Lei n. 10.973, de 2 de dezembro de 2004. Brasília, 2004a. Disponível em: http://www.planalto.gov.br/ccivil_03/_ato2004-2006/2004/lei/110.973.htm. Acesso em: 10 jun. 2018.

BRASIL. Casa Civil. Lei n. 11.196, de 21 de novembro de 2005. Brasília, 2005. Disponível em: http://www.planalto.gov.br/ccivil_03/ato2004-2006/2005/lei/111196.htm. Acesso em: 10 jun. 2018.

BRASIL. Ministério da Ciência e Tecnologia. Livro Verde - Ciência, Tecnologia e Inovação: desafio para a sociedade brasileira. Brasília: MCT, 2001.

BRASIL. Ministério da Ciência e Tecnologia. Livro Branco: Ciência, Tecnologia e Inovação. Brasília: MCT, 2002.

BRASIL. Ministério da Ciência e Tecnologia. Livro Azul: conclusões da $4^{\text {a }}$ Conferência Nacional de Ciência, Tecnologia e Inovação. Brasília: MCT, 2010a.

BRASIL. Ministério da Educação. Coordenação de Aperfeiçoamento de Pessoal de Nível Superior. Plano Nacional de Pós-graduação - PNPG (2005-2010). Brasília: CAPES, 2004b. 
BRASIL. Ministério da Educação. Coordenação de Aperfeiçoamento de Pessoal de Nível Superior. Plano Nacional de Pós-graduação - PNPG (2011-2020). Brasília: CAPES, 2010b.

BRASIL. Decreto n. 7642, de 13 de dezembro de 2011. Institui o Programa Ciência Sem Fronteiras. Brasília, 2011. Disponível em: http://www.planalto.gov.br/ccivil_03/_ato20112014/2011/decreto/d7642.htm. Acesso em: 13 nov. 2019.

CASTRO, Alda Maria. Internacionalização do ensino superior: estratégia de solidariedade ou de mercado? Natal: AFIRSE, 2010. p. 1-24.

CASTRO, Alda Maria; CABRAL NETO, Antonio. O ensino superior: a mobilidade estudantil como estratégia de internacionalização na América Latina. Revista Lusófona de Educação, Lisboa, n. 21, 2012.

CHAVES, Vera Lúcia. Expansão da privatização/mercantilização do ensino superior Brasileiro: a formação dos oligopólios. Educ. Soc., Campinas, v. 31, n. 111, p. 481-500, jun. 2010.

COX, Pamela. Foreword. In: DE WIT, Hans et al. Higher education in Latin America: the international dimension. Washington, DC: World Bank, 2005. Disponível em:

https://openknowledge.worldbank.org/bitstream/handle/10986/7428/343530PAPER0LA1010 FFICIALOUSE0ONLY1.pdf?sequence=1. Acesso em: 10 jun. 2018.

DE WIT, Hans. Internationalisation of highr education: an introduction on the why, how and what. In: WIT, Hans (ed.). An introduction to higher education internationalisation. Milan: Centre for Higher Education Internationalisation (CHEI), Università Cattolica del Sacro Cuore, 2013. p. 13-46.

KATO, Fabíola Bouth. A nova política de financiamento de pesquisas: reforma no Estado e no papel do CNPq. 2013. Tese (Doutorado em Educação) - Centro de Educação e Ciências Humanas, Universidade Federal de São Carlos, São Paulo, 2013.

KATO, Fabíola Bouth; FERREIRA, Luciana Rodrigues. A política de expansão e financiamento da pós-graduação: as diretrizes do PNPG (2011-2020) e PNE (2014-2024).

Revista Brasileira de Política e Administração da Educação, Goiânia, v. 32, n. 3, p. 677698, set./dez. 2016.

KNIGHT, Jane. GATS - Higher education implications, opinions and questions. In: FIRST GLOBAL FORUM ON INTERNATIONAL QUALITY ASSURANCE, ACCREDITATION AND THE RECOGNITION OF QUALIFICATIONS IN HIGHER EDUCATION, 1., 2002, p. 1-17. Paris. Annals [...]. Paris: Unesco, 2002. Theme: Globalization and higher education.

KNIGHT, Jane. An internationalization model: responding to new realities and challenges. In: DE WIT, Hans et al. Higher education in Latin America: the international dimension. Washington, DC: World Bank, 2005. Disponível em: https://openknowledge.worldbank.org/bitstream/handle/10986/7428/343530PAPER0LA1010 FFICIAL0USE0ONLY1.pdf? sequence=1. Acesso em: 10 jun. 2018. p. 1-38. 
LIMA, Manolita Correia; CONTEL, Fabio Betioli. Internacionalização da educação superior: nações ativas, nações passivas e a geopolítica do conhecimento. São Paulo: Alameda, 2011.

LIMA, Manolita Correia; MARANHAO, Carolina Machado. O sistema de educação superior mundial: entre a internacionalização ativa e passiva. Avaliação, Campinas; Sorocaba, v. 14, n. 3, nov. 2009. Disponível em:

https://www.scielo.br/j/aval/a/5VJDvJnkgsDn9nmwWCCvKbj/abstract/?lang=pt. Acesso em: 10 jun. 2018.

MANCEBO, Deise. Reflexões sobre a pós-graduação no Brasil: novos rumos e pragmatismo como fundamento. In: CHAVES, Vera Lúcia Jacob; SILVA JÚNIOR, João dos Reis (org.). Educação superior no Brasil e diversidade regional. Belém: Editora da UFPA, 2008. p. 171-187.

MOROSINI, Marília Costa. Estado do conhecimento sobre internacionalização da educação superior: conceitos e práticas. Educ. rev., Curitiba, n. 28, dez. 2006.

MOROSINI, Marília Costa; NASCIMENTO, Lorena Machado. Internacionalização da educação superior no Brasil: a produção recente em teses e dissertações. Educ. rev., Belo Horizonte, v. 33, e155071, 2017.

SIUFI, Gabriela. Cooperación internacional e internacionalización de la educación superior. Revista Educación Superior y Sociedad (ESS), Caracas, v. 14, n. 1, p. 119-146, out. 2009.

THIENGO, Laura Carlette. Universidade de classe mundial, ou, $O$ fim da universidade como universitas? Campinas: Mercado de Letras, 2019. 